\title{
Developing Partnerships with the Fire Service to Enhance Fire Protection Engineering Education Opportunities
}

\author{
David Torvi \\ Department of Mechanical Engineering \\ University of Saskatchewan \\ 57 Campus Dr., Saskatoon, SK S7N $5 A 9$ \\ david.torvi@usask.ca
}

\begin{abstract}
Fire protection engineering is increasing in importance in Canada and other countries, especially with recent changes to building and fire codes. Fire protection engineering design is highly interdisciplinary, which can present challenges when developing courses in this area. At the University of Saskatchewan, this challenge has been partially addressed through partnerships with the fire service, and other universities and research organizations. This paper discusses the importance of considering the fire service in the design process, and provides examples of partnerships with the fire service in the Mechanical Engineering undergraduate program and in graduate research projects.
\end{abstract}

\section{Introduction}

In 2005, Canada introduced objective-based national building and fire codes. Like many other countries around the world, these codes have been developed in order to allow engineers more flexibility when designing fire protection and other systems. While previous building codes in Canada have prescribed many of the details of fire protection systems, the new codes will allow engineers to develop alternative designs as long as these designs can be shown to meet the objectives of the code and appropriate performance requirements. The new codes are expected to result in innovative designs that are safer and more cost-effective.

An important part of the transition to objectivebased codes is the development of design tools that will allow engineers to determine if their designs meet the objectives and corresponding performance requirements. These tools range from engineering correlations to computational fluid dynamics models of fire in buildings. These tools all require a deeper knowledge of fire behaviour than the previous codes. Experience in other countries that have adopted similar codes has shown that in order to take full advantage of the new codes, Canada must increase educational opportunities in fire protection engineering (FPE).
Fire protection engineering design is highly interdisciplinary, involving all engineering disciplines, and many natural and social sciences. For example, if an engineer is to evaluate the consequences of a fire in a particular room, they will first need to determine the most likely fire scenarios, often using fire statistics. For each of the most common fire scenarios, the engineer will then have to estimate the rate of fire growth, and the heat fluxes, temperatures and gas concentrations at various points in the room. These estimates are based on an understanding of the combustion process, as well as the heat transfer and fluid mechanics associated with the fire.

Fire will affect occupants, and the building and its contents. The effects of fire on occupants will depend on the reaction of people to fire, which depends on factors such as fire cues (e.g., smoke), the perceived threat, and detection and communication systems in the building. Once people decide to leave a space, the time for them to escape will depend on the rate at which they evacuate, which affects their exposure to high temperatures and heat fluxes, and combustion products. Therefore, besides engineering science, predictions of the effects of fire on people involve areas such as psychology, kinesiology, and physiology. The effects of fire on structures and the contents of a building will be governed by heat transfer in materials, which in turns depends on the temperature-dependent properties of these materials. 
Therefore, these calculations require knowledge of heat transfer, material science, and structural engineering.

While clearly there is a need in fire protection engineering for individuals with expertise in each of the areas of science and engineering described above, any fire protection engineer should have a working knowledge of many different areas within engineering, such as combustion, heat transfer, structural engineering, material science, and control systems. A fire protection engineer also needs to be aware of areas outside of engineering, such as the psychology of human response to fire. Therefore, complete undergraduate and graduate fire protection engineering programs often include courses from a wide variety of areas within and outside of engineering [1].

It is also important for a fire protection engineer to be able to work closely with various stakeholders outside of the engineering community. For example, from the initial stages of design through to commissioning and day-to-day operations, fire protection engineers work closely with building officials, some of who may not be engineers, to ensure that appropriate building and fire code requirements are met. Engineers who are involved in fire investigations work closely with the legal profession, and in some cases government officials and the general public.

One of the most important set of stakeholders that fire protection engineers work with is the fire service. Fire protection engineers and the fire service have the same two main goals: to prevent fires from occurring and to minimize the effects of any fires that do occur. Fire prevention is addressed by engineers in both building design and in the development of operating procedures. Fire departments may be involved in the approval of these designs and operating procedures. The fire service is involved in regular inspections of facilities to ensure compliance with fire codes and other requirements, in order to help prevent fires. As all fires cannot be prevented, engineers must also take into account fire department operations in design, so as to assist the fire service is minimizing the effects of any fires that do occur.

While fire protection engineers and the fire service share the same goals, they may not always maintain a running dialogue. However, experience has shown that there are many areas in which collaborations between these two groups can have significant benefits to both parties. For example, fire departments can benefit from the new technology being developed by engineers, and as researchers improve their understanding of fire phenomena, this will assist firefighters to suppress fires in a safer, more efficient fashion. Including firefighters in the design process can help engineers to develop buildings and facilities that are safer, and can reduce delays in commissioning due to code issues. The hands-on experience that firefighters bring to the table can assist engineers and researchers to better understand fire phenomena.

This paper discusses the current state of fire protection engineering education in Canada. The objectives and content of a technical elective course in fire protection engineering are described, along with the challenges in teaching courses in this area. The paper then provides examples of specific ways in which collaborations with the fire service have been formed during the development of the course, along with the benefits of these collaborations. While the focus of this paper is how the fire service can assist in the delivery of courses in fire protection engineering, examples of collaborations in capstone design courses and graduate student research projects are also provided.

\section{FPE Education in Canada}

There are very limited fire protection engineering educational opportunities in Canada. While a number of universities across Canada do research in topics related to fire and explosions, only four engineering schools offer courses in the area of fire protection engineering [2]. Concordia University offers an elective to undergraduate and graduate students in fire and smoke control in buildings. The University of Waterloo offers an undergraduate elective in fire safety engineering, and is in the process of expanding its graduate courses in this area. Carleton University offers a series of graduate courses in fire safety engineering.

Since 2001, the University of Saskatchewan has offered an undergraduate elective, which is designed to introduce students to the field of fire protection engineering. ME 478 is open to students in the third or fourth year of the Mechanical Engineering program. Like other technical electives in the department, the course is scheduled to be given every two years. The course has proven to be very popular, as the average enrollment was approximately 45 students the last three times it was offered. 


\section{Objectives and Content of ME 478}

The main objective of ME 478 is to teach students the basics of fire science, including important theory from heat transfer, fluid mechanics, thermodynamics and other fields. Much of this material is an extension or a review of material from their other mechanical engineering courses. Students also learn how to use simple fire models to design fire protection systems for buildings, such as sprinklers, detectors and building construction features. As much of fire protection engineering design is based on selecting materials using the results of standard tests, students also learn about the main fire test methods used in industry, and how to analyze data from these tests.

Some of the topics in ME 478 are important not only in fire protection engineering, but in other areas of engineering design. These topics may not be covered in great detail in other mechanical engineering courses. For example, students learn the process used by standards organizations, such as the American Society for Testing and Materials (ASTM) or the Canadian General Standards Board (CGSB), to develop standard test methods. Building and fire codes are important not only in fire protection system design, but in the design of heating, ventilation and other building systems.

One of the main goals of the course from an instructor's point of view is to increase awareness of fire protection engineering in the design process for buildings and other facilities. This is important as many mechanical engineering students will end up being involved in the design of building or other facilities during their career, and in some industries fire protection system design has traditionally not been given the same consideration as other elements of design. In fact, the history of fire protection engineering has shown that most of the major developments in this field have occurred as a reaction to a major fire tragedy, rather than as the result of continual progress in the area.

It is also hoped that some of the students will decide to seek employment in the fire protection field in the future, which will help to address the need for more fire protection engineers in Canada. Some of the students who have taken this course in the past have also decided to pursue graduate fire science thesis research, either at the University of Saskatchewan or other universities. As opportunities for distance and on-line education for professionals in the fire protection area have continued to increase, another important aspect of this course is to make students aware of these opportunities should they wish to specialize in this area at some time after graduation.

Based on these goals, the philosophy in the design of the course has been to provide a broad overview of this area, rather than to concentrate a few aspects of fire science, such as a detailed study of the behavior of fire in a room, or smoke control systems. The specific topics covered in ME 478 include:

- the history of fire protection engineering and its impact on progress in this field,

- building and fire codes,

- combustion,

- heat transfer in fires,

- flammability limits,

- fire testing,

- fire plume equations and predicting sprinkler and detector activation times,

- ignition of solids,

- fire growth,

- smoke production and movement,

- fire investigations,

- human behaviour in fires,

- the effects of fire on humans, and

- the role of the fire service in building design.

Some of the topics near the end of this list are at least partially based on theory outside of engineering. Fire testing is typically conducted in large-scale facilities that are only available in limited locations. Therefore, partnerships have been developed with other organizations to help teach various parts of the course.

One example is a series of videoconferences that have been arranged with experts from the National Research Council of Canada (NRC), who have given guest lectures on topics such as human behaviour in fire and the investigations into the collapse of the World Trade Center towers on September 11, 2001. Other organizations such as NRC or the National Institute of Standards and Technology (NIST) in the U.S. have provided videotape of fire tests conducted in their labs. This has been particularly important as the University of Saskatchewan does not have full-scale fire test facilities. As some of these partnerships have been discussed in a previous paper [3], the emphasis of this paper is on partnerships that have been developed with the fire service in order to teach portions of ME 478. Partnerships with the fire service in the Department of Mechanical Engineering's capstone design course and in graduate research projects are also briefly described. 


\section{Fire Service Collaborations in ME 478}

In order for students to begin to develop a dialogue with the fire service, several activities have been included in ME 478. During the first offerings of the course, a tour was arranged of the main fire hall in Saskatoon. This allowed students to see fire trucks, equipment and the 911 communications centre. While, such tours are often thought of as being primarily for K-12 students, they are also of benefit to engineering students who will be involved in building design. For example, an important operational issue for the fire department is being able to get their large fire trucks and other equipment as close as possible to the building and to the water supply. Other issues include designing communications systems that can be used to provide instructions to occupants, and ensuring that elevators and stairwells are designed to facilitate fire department operations. This tour provided an opportunity for the fire department to directly communicate these and other design criteria to future engineers. Students also were able to see new technology that has been developed to assist firefighters. For example, students were able to try out thermal imaging technology. This in turns assists in teaching the radiation heat transfer portion of the course.

As the number of students enrolled in the class has increased, the fire hall tour has been replaced by a guest lecture by a fire investigator with the local fire department. In this presentation, the fire investigator walks the students through a past investigation, discussing the steps that are taken to determine the cause and point of origin of the fire. This discussion complements the portions of the course that describe the main stages of fire growth and the effects of fire on structures. Visual clues that investigators use to reconstruct the fire (e.g., the extent of charring) can also be compared with the students' knowledge of the typical temperatures and heat fluxes in a fire. Many student evaluations have identified this guest lecture as one of the highlights of the course. Some students have also expressed an interest in working in the field of forensic engineering after graduation, and have been put in contact with engineers in this field for further information.

As mentioned earlier in this paper, a key stakeholder that fire protection engineers deal with is the building official. Many engineers may also be involved in developing operational procedures for a building or facility. Therefore, a guest lecture and tour has been arranged with the individual in charge of fire safety at the University of Saskatchewan each year that the course has been offered. The guest lecture discusses important operational issues, such as regular inspections of extinguishers and other fire protection systems, fire evacuation drills and plans, and interactions with the fire department. A tour is held so that students can visit the sprinkler room of a building on campus. Students are also shown other fire protection systems in buildings on campus. For example, tours of the Canadian Light Source synchrotron and buildings with large atria have been arranged. These tours of relatively large buildings help to illustrate the challenges of providing fire protection in these sizes of space, such as the long period of time it could take for fire gases to reach the ceiling and to activate fire detection equipment.

In summary, involving the fire service in ME 478 allows a wider variety of issues to be addressed. It also helps the students to begin to realize the importance of including the fire service in the design process as early as possible. Students realize the importance of fire code requirements when developing operating procedures and the inspection requirements for fire protection systems. Some students have also become interested in pursuing the opportunities that exist for engineers either in the fire service or in closely related fields, such as forensic engineering.

\section{Fire Service Design Projects}

Besides assistance in offering ME 478, another result of the partnership with the fire service has been the opportunities for capstone design projects. This has been of benefit to both the fire service and to students in the department. In the past few years, two projects in the Mechanical Engineering capstone design course [4] have involved Saskatoon Fire and Protective Services, and one project has been supplied by the Forest Engineering Research Institute of Canada and the Saskatchewan Forest Centre. Students designed a diesel vehicle exhaust extraction system for a new concept fire house in Saskatoon, and a system for testing ladders for the fire department. Another group designed an improved system for igniting prescribed forest fires from helicopters. Feedback from the students' clients has been very positive and the clients have expressed interest in working on future student design projects.

\section{Fire Service Research Projects}

Besides the collaborations in the undergraduate program, the fire service has also provided assistance in graduate research projects. As mentioned earlier, the University of Saskatchewan does not have full- 
scale fire test facilities. Most fire departments have training facilities, and many departments are involved in field fire training exercises, which utilize buildings that are scheduled for demolition. Three examples of research projects that have used fire department facilities or have been conducted during fire department exercises are presented in this section.

In October 2002 during Fire Prevention Week, the fire research group at the University of Saskatchewan assisted Saskatoon Fire and Protective Services in a public demonstration (Figure 1). By equipping the department's training facility with thermocouples, real time temperature measurements could be relayed to the public attending the event, further educating them in the dangers of fire. The data obtained in this experiment was also used by a graduate student who was investigating the conditions that firefighters are subjected to during their duties. This data was used to help select heat flux levels used in laboratory tests to determine how certain properties of firefighters' clothing change over the useful lifetime of this gear [5]. The local fire department also assisted the research group by obtaining samples of the materials used in their protective clothing from their supplier.

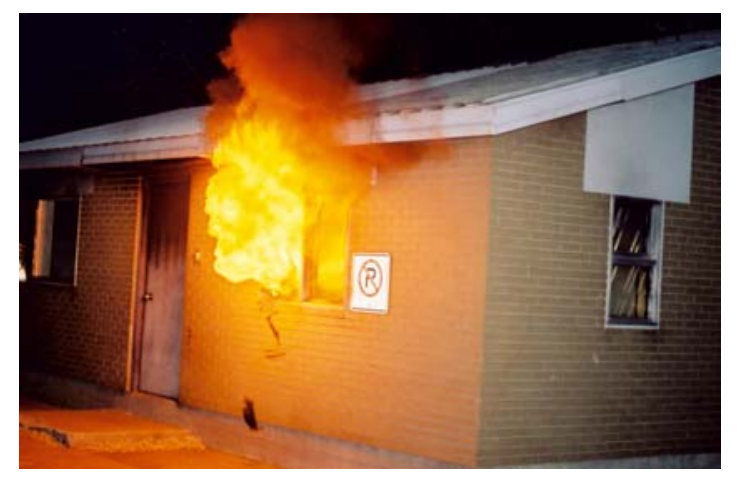

Figure 1. Public demonstration, Fire Prevention Week, Saskatoon, 2002

In July 2003, further data on the conditions that firefighters are subjected to during the course of their duties was obtained during a fire department training exercise in Edmonton $[5,6]$. Heat fluxes within and outside an abandoned house were measured, along with temperatures inside the house, during a series of three burns that were confined to a single room of the house. Data was also obtained during a final burn in which the house was burned to its foundation (Figure 2). Graduate students gained valuable experience in field fire testing and obtained data they would not have been able to get otherwise. As this burn also involved researchers from other universities, including those from outside engineering, students were also able to make valuable contacts and to get a better appreciation for the scope of fire research.

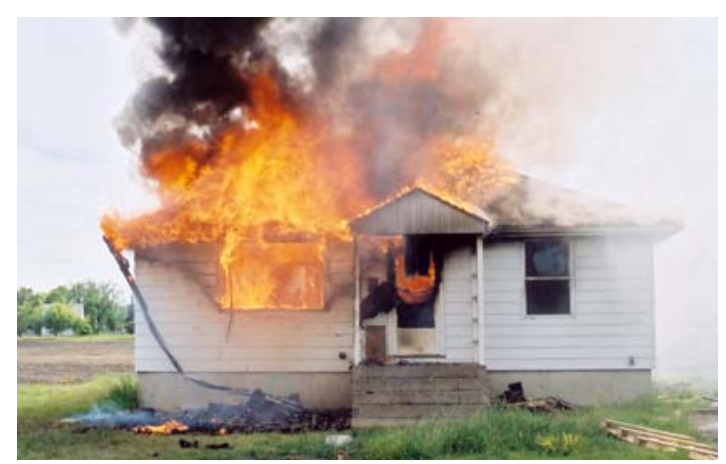

Figure 2. Field fire test, Edmonton, 2003

In September, 2004, another set of field fire tests was conducted in Edmonton as part of a fire investigators course. Three mattress fires were set in one room in an abandoned office building (Figure 3). Temperatures and heat fluxes were again measured, so that these sets of data could be compared with predictions made using fire protection engineering correlations [6]. Once again, the student gained valuable experience in field fire testing. The student was also able to witness a number of other tests, including some explosion testing and car fires, and met forensic engineers who were participating in the course in order to learn about this area of interest.

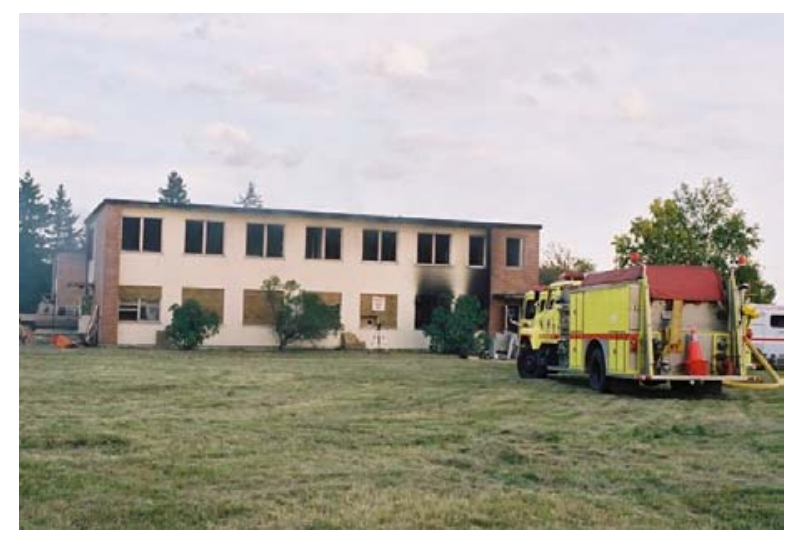

Figure 3. Field fire test, Edmonton, 2004

While these collaborations were primarily for graduate student research projects, results from these studies have also been used in ME 478. For example, the section of the course dealing with fire testing not only discusses standard tests conducted in laboratories, but also the importance of conducting field fire tests in 
actual buildings. Temperatures measured in the 2004 tests are compared with predictions made using the equations the students learn in ME 478.

\section{Conclusions and Future Work}

Fire protection engineers and the fire service share common goals: preventing fires and minimizing the effects of fires that do occur. Dialogues between these groups are very important to fire protection system design, as these discussions lead to systems that are safer and more efficient. Partnerships between these two groups provide a number of other benefits to both parties. In the academic setting, these partnerships have also assisted in the delivery of courses in fire protection engineering, capstone design courses, and graduate research projects. The fire department can provide unique expertise and facilities to universities, while universities can provide technical advice and assistance. The results of fire research can be transferred to fire departments, and ultimately will lead to safer conditions for occupants and firefighters.

The fire service will continue to be an important part of ME 478 in the future. Further opportunities for guest lectures will be explored. Further mattress fire tests have been planned in conjunction with fire department training exercises. In the longer term, one particular area of interest is to compare the fire behaviour of materials in standard fire test facilities and in fire department training facilities. This is important to the fire service, as they may wish to use their facilities during fire investigations or in the evaluation of new products for buildings. The knowledge gained in this research will help them to compare their observations with what might be expected during standard tests in the laboratory.

\section{Acknowledgements}

The author would like to acknowledge the assistance that has been provided by the following individuals from the fire service in ME 478: Chiefs Bill Hewitt and Brian Bentley, and Dave Bykowy of Saskatoon Fire and Protective Services, and Larry Riopka of the Department of Health, Safety and Environment at the University of Saskatchewan. Assistance provided by the NRC and NIST, the City of Saskatoon, the Forest Engineering Research Institute of Canada, and the Saskatchewan Forest Centre is also gratefully acknowledged.

The author would also like to thank the Edmonton Fire Department, the Fire Investigation Association of Alberta and Crystal Samborski for the opportunity to participate in field fire tests in Edmonton. Graduate student research described in this paper was conducted by Peter Thorpe and Todd Threlfall. Financial support for this research was provided by the Natural Sciences and Engineering Research Council, and the University of Saskatchewan's College of Graduate Studies and Research and Department of Mechanical Engineering. Technical support provided by Dr. Doug Dale and Mark Ackerman of the University of Alberta is also gratefully acknowledged.

\section{References}

[1] S.E. Magnusson, et al., "A Proposal for a Model Curriculum in Fire Safety Engineering", Fire Safety Journal, vol. 25, pp. 1-88, 1995.

[2] D.A. Torvi, "Education: Learning About Fire", Canadian Consulting Engineer, vol. 42, pg. 28, May, 2001.

[3] D.A. Torvi, "Teaching Fire Protection Engineering Within the Mechanical Engineering Curriculum", in Proc. ASEE, 2002, paper 0070.

[4] G.J. Schoenau, "A Final Year Design Course Based on Industry Derived Projects", in Proc. $2^{\text {nd }}$ Int. CDEN Conf., 2005.

[5] P. Thorpe, "Development of Non-destructive Test Methods for Assessment of In-Use Fire Fighter's Protective Clothing", M.Sc. thesis, University of Saskatchewan. 2004.

[6] T.G. Threlfall, "Investigation of Methods Used to Predict the Heat Release Rate and Enclosure Temperatures During Mattress Fires", M.Sc. thesis, University of Saskatchewan. 2005. 